\title{
DISCURSIVIDADE E ALFABETIZAÇÃO: 30 ANOS DIALOGANDO COM ANA LUIZA SMOLKA
}

\author{
Discursivity and literacy: 30 years dialogging with Ana Luiza Smolka
}

Sabrina Guedes de Oliveira - SME/UNICARIOCA/Brasil

Mônica Ramos da Costa Macedo - SME/RIO/Brasil

\begin{abstract}
RESUMO: Este artigo rememora e resgata o livro "A Criança na Fase Inicial da Escrita", de Ana Luisa Smolka, em seus 30 anos de publicação. Nosso objetivo é trazer as questões, inquietações que à época eram pertinentes para pensarmos e refletirmos sobre a fase inicial da escrita nos dias atuais. Dialogaremos com a autora a fim de repensarmos o assunto de outrora, trazendo assim como Smolka, a interlocução para o palco do compromisso docente no processo de aquisição da escrita, isto é, fundamentalmente no período denominado de alfabetização. $O$ artigo não pretende esgotar o assunto, mas reavivar as teorias e teóricos que embasaram o seu trabalho, especialmente Bakhtin. Além disso, Geraldi que nos nossos dias, vem aquecendo o debate sobre a discursividade ao transitar pelos espaços acadêmicos e chegando à escola, permitindo que os novos pesquisadores e os professores regentes assumam a responsabilidade pela alfabetização dos sujeitos num movimento reflexivo sobre os processos linguiísticos. Ao finalizarmos este artigo, trazemos a releitura das discussões que na atualidade se fazem pertinentes e nos questionam enquanto educadoras alfabetizadoras brasileiras a repensarmos as nossas práticas e levantarmos um debate que não se esgota, mas precisa adentrar o espaço escolar.
\end{abstract}

Palavras-chave: Alfabetização. Discursividade. Interlocução.

ABSTRACT: This article has the purpose of recalling, rescue the book "The Child in the Initial Phase of Writing", by Ana Luisa Smolka, in its 30 years of publication. Our goal is to bring the questions, concerns that at the time were pertinent to think and reflect on the initial phase of writing today. We will talk with the author in order to rethink the subject of yesteryear, thus bringing Smolka, the interlocution to the stage of the teacher's commitment in the process of acquiring writing, that is, fundamentally in a so-called literacy period. The article is not intended to exhaust the subject, but to revive the theories and theorists who grounded his work, especially Bakhtin. In addition, Geraldi, who today is warming up the debate about discursivity by passing through academic spaces and arriving at school, allowing new researchers and regent teachers to assume responsibility for the literacy of the subjects in a reflexive movement on the linguistic processes. At the end of this article, we bring the re-reading of the discussions that are currently relevant and question us as Brazilian literacy educators to rethink our practices and raise a debate that is not exhausted, but needs to enter the school space.

Keywords: Literacy. Discursiveness. Interlocution.

\section{INTRODUÇÃO}

Educação, Psicologia e Interfaces, Volume 3, Número 3, p. 28-42, Janeiro/Abril, 2019.

ISSN: 2594-5343. DOI: https://doi.org/10.37444/issn-2594-5343.v3i1.125 
A professora Ana Luiza Bustamante Smolka vem se dedicando ao campo da educação com uma persistência no foco das práticas discursivas, colocando em evidência a linguagem como prática social e os processos de aprendizagem e de ensinagem que ocorrem na sala de aula nessa perspectiva, como ela mesma coloca:

\begin{abstract}
Quando, há três décadas, argumentei sobre o modo de conceber a alfabetização como processo discursivo, as idéias que ancoravam essa concepção se aproximavam do que tem sido designado como letramento, implicando, portanto, as condições concretas de imersão dos sujeitos no mundo da escrita, das práticas de leitura e escrita em uso e em transformação, incluindo as práticas midiáticas e a informatização. Destacava nessa proposta, três pontos principais: os modos de participação das crianças na cultura; os diversos modos de apropriação da forma escrita de linguagem pelas crianças; as relações de ensino (SMOLKA, 2012, p.13).
\end{abstract}

No contexto do período, havia uma "disputa" de teorias (Piaget, Vygotsky e Ferreiro) que colocava aspectos e relações com a questão da aprendizagem da língua e da aprendizagem como um todo, o que se constituía num momento de grande efervescência, de problematizações em torno das questões tratadas por ela. Além disso, Smolka trabalhava com princípios da alteridade, da dialogia e da historicidade. E nesse sentido, introduz Mikhail Bakhtin, que é um teórico bastante interessante.

Sobre isso, podemos dizer que Bakhtin apresenta uma visão dialógica da linguagem, propondo uma visão pluralista, polissêmica e polifônica em que coloca três dimensões no processo de formação do eu: eu para mim (como me percebo, minha própria consciência), eu para os outros (como apareço aos olhos dos outros (como apareço aos olhos dos outros) e o outro para mim (como percebo o outro). Em termos de contexto da época, o trabalho de Smolka foi essencialmente inovador, pois até então, mesmo com a divulgação dos teóricos acima citados, o trabalho com a linguagem estava totalmente engessado em cartilhas e métodos que desconsideravam uma visão mais sistêmica da língua. Assim, aprender a ler e escrever dá à palavra um lugar de excelência na constituição da consciência do sujeito leitor e escritor.

Assim, Smolka apontava para a necessidade da escola rever suas condições de escolarização tanto no espaço público, quanto no particular para não continuar reproduzindo práticas de leitura e de escrita mecânicas que por seu curso, concorrem para a evasão e uma visão distorcida da capacidade das crianças e do próprio sistema

Educação, Psicologia e Interfaces, Volume 3, Número 1, p. 28-42, Janeiro/Abril, 2019. 
linguiístico. Ela traz em seu trabalho conceitos como a importância da dialogia, que na linha de Bakhtin:

[...] sustenta que a unidade real da língua é o enunciado posto em diálogo: "a interação de pelo menos duas enunciações". Como mundo partilhado, lida-se com o inconcluso, com uma realidade em constante formação. Nesse mundo partilhado, afirma Bakhtin, vive-se "em um mundo de palavras do outro, de tal modo que as complexas relações de reciprocidade com a palavra do outro em todos os campos da cultura e da atividade completam toda a vida do homem". A alternância dos sujeitos do discurso é uma das características do diálogo, que exige um princípio absoluto e um fim absoluto na ação de cada falante. Essa conclusibilidade específica do diálogo garante a ação responsiva e estabelece relações de pergunta, objeção, aceitação, ordem etc. O diálogo real entre dois falantes é constituído por ao menos dois enunciado s plenos a acabados, e se constitui na forma mais simples e clássica da comunicação discursiva (GLOSSÁRIO, BAKHTIN, 2011, s/p).

Uma vez que a escrita e a leitura não são processos dados, mas sim constituídos através de relações histórico culturais em que o conhecimento da língua acontece, portanto, enunciativos.

Se procurarmos diferenciar enunciado de enunciação, ao levarmos em conta a natureza dialógica da comunicação discursiva, tal diferenciação perde sua importância. Vemos que o enunciado é compreendido como elemento da comunicação em relação indissociável com a vida. Neste sentido, o enunciado concreto é um evento social e não pode ser reduzido a abstrações. Em "Marxismo e filosofia da linguagem" a palavra enunciação é utilizada muitas vezes como ato de fala. A enunciação concreta é a realização exterior da atividade mental orientada por uma orientação social mais ampla, uma mais imediata e, também, a interação com interlocutores concretos. Em "Os gêneros do discurso", o enunciado é definido como a unidade real da comunicação discursiva, diferenciando esta unidade (real) das unidades da língua, como palavras e orações (convencional). Neste texto, Bakhtin discute as três principais peculiaridades do enunciado como unidade real da comunicação discursiva: 1. alternância dos sujeitos falantes; 2. conclusibilidade; 3 . escolha de um gênero discursivo. É neste texto também que Bakhtin afirma que "o desconhecimento da natureza do enunciado e a relação diferente com as peculiaridades das diversidades de gêneros do discurso em qualquer campo de investigação linguística redundam em formalismo e em uma abstração exagerada, deformam a historicidade da investigação, debilitam as relações da língua com a vida (GLOSSÁRIO, BAKHTIN, 2011, s/p).

Educação, Psicologia e Interfaces, Volume 3, Número 3, p. 28-42, Janeiro/Abril, 2019.

ISSN: 2594-5343. DOI: https://doi.org/10.37444/issn-2594-5343.v3i1.125 
Outro aspecto de seu trabalho é quanto ao chamado "erro de escrita" que na verdade são pistas de como a criança está pensando as relações que aí se apresentam. E é nesse, sentido, que o professor precisa avançar em seus conhecimentos lingüísticos ao mesmo tempo em que coloque as certezas de sua prática em dúvida, para que o processo vá o tempo todo sendo problematizado em função do que se apresenta. São os esquemas de representação da língua que a criança estabelece que devem ser fonte de constante processo de entendimento por parte do professor. É um trabalho que nos faz refletir o que acontece ou não para o fracasso escolar da alfabetização.

Smolka traz uma reflexão bastante contundente sobre o processo de alfabetização e como o professor, importante mediador dessa trajetória, é um elemento fundamental.

Para Smolka, o processo de elaboração do conhecimento pressupõe um mediador, conforme uma das contribuições de Vygostky, pela "Zona Proximal de Desenvolvimento" (ZDP), que estabelece que a "criança fará amanhã, sozinha, o que hoje faz em cooperação", evidenciando o papel "regulador" do adulto, ou seja, aquele que faz uma ponte ente o conhecimento adquirido e o conhecimento por adquirir.

Nesta mediação, os signos linguísticos "constituem de um instrumental cultural" de caráter altamente simbólico gerador de novas formas de pensamento. Mais do que isso, a linguagem por ser uma atividade criadora e constitutiva do conhecimento e transformadora, é nela, por e com ela que o homem elabora "novas formas de comportamento, relacionamento e pensamento", e assim, transforma a natureza do próprio desenvolvimento em sócio-histórico (TAFARELLO, 2006, p. 72).

\section{A ALFABETIZAÇÃO COMO PROCESSO DISCURSIVO - A PESQUISA}

Smolka apresenta uma pesquisa com professoras da educação básica em que analisa as práticas docentes no que tange à fase inicial da escrita das crianças. A autora aponta, dentre várias análises, como a discursividade da criança é desprezada pela escola, colocando-a como um sujeito incapaz diante do trabalho com a língua. Ela recorre a alguns conceitos de Vygostky e de Bakhtin para analisar situações em que a linguagem é foco ativo do processo nas relações de mediação pedagógica. Compartilhando conosco, Smolka (2012, p.13) nos diz que:

Educação, Psicologia e Interfaces, Volume 3, Número 1, p. 28-42, Janeiro/Abril, 2019.

ISSN: 2594-5343. DOI: https://doi.org/10.37444/issn-2594-5343.v3i1.125 
Assumindo uma concepção de linguagem como prática social, como produção e produto da atividade humana, constitutiva dos sujeitos em interação, buscava compreender, com uma equipe de trabalho que desenvolvia projetos de atuação e investigação no espaço escolar, o dinâmico e complexo processo de elaboração coletiva de conhecimento - da língua, da linguagem, do mundo, da leitura e da escrita, da literatura, dos modos de ensinar e a ler e escrever.

Vygotsky fala um pouco desse conceito dizendo que o discurso que a criança verbaliza é em decorrência da transição do discurso social externo para o discurso interior. De tal forma que a realidade social e funcional da palavra, entre demais coisas, é que vai tecendo a subjetividade do sujeito. Portanto, esse discurso do sujeito carrega as marcas dessa inserção social, de suas interações e valores que ele vai atribuindo e mediando e sendo mediado. Vygostky $(1975$, p.51) nos fala a esse respeito que:

O pensamento verbal não é uma forma inata, natural, de comportamento, mas é determinado por um processo histórico-cultural e tem propriedade e leis específicas que não podem ser encontradas nas formas de pensamento e da fala.

Assim, no período em que o sujeito aprendente ingressa na escola, ele está imerso numa cultura linguística que já o constitui e que a partir dos processos de aprendizagem escolares sofrerá outras interferências se (re) constituindo o tempo todo. “A própria cultura reelabora em profundidade a composição natural da conduta, dando uma orientação completamente nova a todo curso do desenvolvimento" (MARTINS, RABATINI, 2011, p. 347).

No entanto, a escola tem se colocado como um mundo à parte do mundo real. Sua lógica apresenta-se muito cartesiana, linear e aqueles que não estiverem adequados a essa padronização podem ser configurados como incompetentes, diferentes. A questão dos métodos de alfabetização como uma padronização de respostas pode comprometer os processos discursivos do aprendente, pois na maioria deles não está colocada a função social da escrita de uma maneira real, significativa. Assim, o processo de alfabetização, na perspectiva discursiva, acaba ficando engessado e a criança acaba não pensando sobre a língua, mas criando formas superficiais de uma pseudo escrita.

Os autores mudam, o momento histórico é outro, mas a forma de conduzir o processo não avança, há sempre um incentivo ao mecanismo da repetição. O professor, nesta perspectiva, continua sendo aquele que ensina e o aluno aquele que aprende, tendo como

Educação, Psicologia e Interfaces, Volume 3, Número 3, p. 28-42, Janeiro/Abril, 2019. 
Discursividade e alfabetização: 30 anos dialogando com Ana Luiza Smolka

pressuposto básico os fundamentos da escola tradicional (SCHLICKMANN, 2011, s/p).

Percebemos o quanto esse processo inicial é sofrido para o aluno quando muito do seu conhecimento prévio é relativizado, ou mesmo inutilizado no contato com o conhecimento que não admite a coloquialidade como forma de ajustamento dos saberes circulantes.

A superficialidade na forma como o conhecimento é apresentado traz uma negação na identidade e no reconhecimento desse aluno como parte importante e fundamento da sua própria aprendizagem.

Smolka coloca que o que aparentemente muitas vezes é tido como um erro, é na verdade uma tentativa do aluno em entender como essa escrita se processa e como ele deve escrever. Na perspectiva discursiva, o aluno vai alçando alternativas de escrita num processo de aproximação da escrita convencional. Ele vai arriscando modos de escrita para se fazer comunicar e com isso, vai testando suas elaborações sobre a língua em que ele está inserido. E isso é que é de fundamental importância nesse início do processo. $\mathrm{O}$ aprendente precisa se sentir produtor do seu próprio pensar e elaborar suas hipóteses sobre a língua que o constitui.

Ele mesmo precisa ter ação sobre a língua que utiliza social e culturalmente. "Na tentativa de considerar o erro não como um fato isolado (na língua), mas como uma instância significativa numa trama mais ampla das relações textuais/sociais" (SMOLKA, 1995. p. 18). A escola precisa ter maturidade e o conhecimento exato de como o aprendente passa pelo processo de aquisição da língua escrita.A importância desse movimento pensante daráa segurança e o protagonismo requerido para a estruturação e a consolidação das novas etapas da aprendizagem desse indivíduo.

Bakthin contribui para essa discussão falando-nos sobre o conceito de palavra como um signo ideológico dizendo que:

Não é por acaso que os pensadores da Antiguidade já concebiam o discurso interior como um diálogo interior. Essas unidades prestam-se muito pouco a uma análise sob a forma de constituintes gramaticais (a rigor, em certos casos, isso é possível, mas com grandes precauções) e não existe entre elas, assim como entre as réplicas de um diálogo, laços gramaticais; são laços de outra ordem que as regem. Essas unidades do discurso interior, que poderiam ser chamadas de "impressões globais de enunciações", estão ligadas umas às outras, e

Educação, Psicologia e Interfaces, Volume 3, Número 1, p. 28-42, Janeiro/Abril, 2019.

ISSN: 2594-5343. DOI: https://doi.org/10.37444/issn-2594-5343.v3i1.125 
sucedem-se umas às outras, não segundo regras da lógica ou da gramática, mas segundo leis de "convergência apreciativa" (emocional), de concatenação de diálogos, etc... e numa estreita dependência das condições históricas da situação social de de todo o curso pragmático da existência. Somente a explicitação das formas do discurso dialogado pode esclarecer as formas do discurso interior e a lógica particular do itinerário que elas seguem na vida interior (SMOLKA, 1981, p.63).

Após algumas breves ideias do trabalho de Smolka, conseguimos perceber que ela nos abre um leque bastante generoso e audacioso de concepção sobre o trabalho com a escrita e a leitura no período do processo de alfabetização. Ela amplia o nosso olhar sobre a necessidade de um trabalho de mediação com uma escrita significativa e socialmente posta, por isso, histórica. Aponta também para os processos intersubjetivos e intrassubjetivos que acontecem na constituição dos sujeitos que estão no mundo e que, nesse momento, realizam um trabalho de aprender como se fazer comunicar, uma vez que essa aprendizagem não é dada, mas aprendida. Além disso, que elaborações o aprendente faz nesse momento e que vão constituindo-lhe, afetando sua autoria e constituindo-o num leitor/escritor. É claro e perceptível, que o aprendente exerce seu direito de aprendizagem, marcando essa trajetória com seus modos de pensar, de falar, de escrever e de ler o mundo no qual está inserido. Nos deixa claro ainda, a amplitude da discursividade face às metodologias acartilhadas que vão dificultando o entendimento sobre a língua.

Percebemos a necessidade vigorosa que a escola necessita de reavaliar seus processos de ensinagem e de mediação com seus alunos. Perceber esse aprendente como autor de seu processo. Nesse sentido, a professora Ludmilla Thomé Andrade em seu artigo Novos Espaços Discursivos na escola, nos chama atenção sobre 5 passos importantes na construção de uma perspectiva discursiva da língua: a voz do aluno, a escrita espontânea, a negociação de sentidos, a refacção do texto e a publicação.

A voz do aluno seriam as suas histórias, suas reflexões sobre o mundo em que está inserido, pois como nativo da língua, a utiliza em situações significativas culturalmente constituídas. Portanto, pensar sobre seu próprio processo de escrita é uma prerrogativa inalienável.

A escrita espontânea é o momento em que suas elaborações sobre essa língua vêm à tona e com isso, o que está pensando sobre essa escrita, que letra utilizar, que combinações pode fazer. E é nesse momento que o registro é demasiado importante

Educação, Psicologia e Interfaces, Volume 3, Número 3, p. 28-42, Janeiro/Abril, 2019. 
para que o professor pense e reflita sobre que hipóteses seu aluno está baseando essa escrita.

O momento da negociação de sentidos se apoia na construção coletiva em que a escrita do aluno se faça compreendida ao outro, que significados, impressões e marcas se fez presente para aquele grupo social. O que queremos dizer com o que escrevemos? Qual a relativização de sentidos podemos pensar? Em que circunstâncias escrevemos? Como e para quem? A refacção é o momento de analisar o escrito, mas comcuidado para não ferir a autoria de quem escreveu. Finalmente, a publicação é a necessidade de todo o texto que é escrito precisa circular, ganhar e se tornar público nos espaços necessários. Vale lembrar que esses processos não seguem uma ordem cronológica, mas sim, a dinâmica da produção escrita. Andrade (2011, p.17) nos diz nesse sentido que:

[...] Mais importantes que do que os ordenamentos sequenciados serão as dosagens e as articulações entre os espaços, bem como o fato em que eles deverão muitas se sobrepor, mesmo que apenas parcialmente.Os espaços se pressupõem, porém numa temporalidade linear, mas numa dimensão de aprendizagem como significações em processo de construção (mútua). Conforme a experiência de letramento desejada e presumida no grupo de atores envolvidos, os espaços assumirão ordens muito diferentes.

No livro Portos de Passagem de Geraldi (2013), temos algumas considerações que acompanham os estudos teóricos de Bakhtin e de certa maneira, dialogam com que Smolka também nos aponta.

A interlocução é um elemento importante no processo de aprendizagem, tornando-se fonte da singularidade e constituição dos sujeitos. "A interlocução, entendida como espaço de produção de linguagem e de constituição de sujeitos" (GERALDI, 2013, p.5).

A interlocução permite a formação da linguagem valorando as informações/conhecimentos circulantes, levando à constantes transformações. "Como vimos com Bakhtin, a consciência dos sujeitos forma-se neste universo de discurso e é deles que cada um extrai, em função das interlocuções de que vai participando" (GERALDI, 2013, p. 33).

Esse movimento que a linguagem executa e sofre determina novos significados à língua, trazendo ao indivíduo um uso real para a sua realidade. Constituir-se aprendente

Educação, Psicologia e Interfaces, Volume 3, Número 1, p. 28-42, Janeiro/Abril, 2019.

ISSN: 2594-5343. DOI: https://doi.org/10.37444/issn-2594-5343.v3i1.125 
da língua materna nesse contexto e nos primeiros anos de escolaridade traz uma qualidade à formação linguística queparticipa dos processos interacionais desse mesmos sujeitos (aprendentes).

Familiarizar o aluno nessa roda de significados é trazer também aquilo que dignifica e é digno de importância para esse mesmo indivíduo, de como ver e se relaciona com o mundo ao seu redor. As ideologias são produzidas neste ambiente e perpassam a aprendizagem do aluno trazendo uma rede de situações que conectam ou segregam este mesmo indivíduo.

As ações da linguagem, quer em sentido estrito de interferência na próprias possibilidades de percepção e de raciocínio linguísticodiscursivo, quer em sentido mais amplo de constituição de um modo de ver o mundo (na construção de sistemas de referências), limitam e estabilizam formas de raciocínio e formas de compreensão do mundo (GERALDI, 2013, p. 57).

Uma sociedade como a nossa, denominada "sociedade de discurso", como o próprio Geraldi assim a chama, possui um arcabouço teórico, linguístico, que a constitui e traz para dentro do universo escolar uma autorização para os utilitários dessa linguagem. De certa maneira, esse movimento passa pelas mãos e intermediação do professor frente ao processo ensino-aprendizagem.

Trabalhar com o discurso, com o texto, é trazer para dentro da escola, da sala de aula, a disputa ideológica que acontece na sociedade. Inserir o "eu" na fala dos outros, trazendo com isso também, outras vozes e enunciados que se sustentam em códigos previamente estabelecidos.

O educador tem a tarefa e a grande responsabilidade de inserir, contextualizando o aluno nesse circuito; produção e interpretação de texto são movimentos que se fazem presentes. "O texto se oferece sempre como uma tensão entre as leituras que lhe são previstas e as leituras que, imprevistas, podem ser construídas” (GERALDI, 2013, p.110).

A escola precisa levar o aluno escritor/autor e leitor ao entendimento das interlocuções e interpretações que ocorrem além do espaço escolar, que ultrapassam os muros escolares e trazem para dentro deste mesmo local o conhecimento de mundo, de vida que necessita ser re(integrado) ao cotidiano de cada elemento envolvido. 
dialogia é o ponto de partida para o trabalho pedagógico profícuo realizado que tem como primeiro suporte o texto.

A presença do texto constrói-se como possibilidade de reapropriação, pelo professor, e pelos alunos, de seu papel produtivo. Por esta vida pode se dar a desconstrução da identidade atual (exercício da capatazia) e a construção de uma nova identidade (GERALDI, 2013, p.113).

Esse trabalho dialógico traz como diz Bakhtin, uma atitude responsiva, uma contrapalavra. $\mathrm{O}$ processo interior e exterior se interccionam; realidades que se encontram e formam identidades. Vozes e enunciados se perfazem no cotidiano trazendo uma qualidade ao trabalho desenvolvido num processo de alfabetização que incorpora estes conceitos.

O desenvolvimento de um trabalho nesta perspectiva leva o fazer pedagógico para uma dimensão onde a discursividade é a tônica. Smolka (2012, p. 22) reforça essa relação:

A relação de ensino parece se constituir nas interações pessoais. Mas a tarefa de ensinar é instituída pela escola, vira profissão (ou missão!) (Será que vira mesmo profissão?). A tarefa de ensinar, organizada e imposta socialmente, baseia-se na relação de ensino, mas, muitas vezes, oculta e distorce essa relação. Deste modo, a ilusão e o disfarce acabam sendo produzidos, não pela constituição da relação de ensino, mas pela instituição da tarefa de ensinar. Em várias circunstâncias, a tarefa rompe a relação e produz a "ilusão". Ou seja, da forma como tem sido vista na escola, a tarefa de ensinar adquire algumas características (é linear, unilateral, estática) porque, do lugar em que o professor se coloca (e é colocado), ele se apodera (não se apropria) do conhecimento; pensa que o possui e pensa que a sua tarefa é precisamente dar o conhecimento à criança. Aparentemente, então, o aprendizado da criança fica condicionado à transmissão do conhecimento pelo professor.

O trabalho de Ana Luisa Smolka nos faz pensar sobre a dimensão do trabalho com a língua e que mesmo após 30 anos continua atual e instigante a olharmos para a nossa prática. Nos faz refletir sobre as condições e funções da escrita em que a língua é um instrumento elaborado pela espécie humana e essa mesma espécie, através de suas relações concretas vai constituindo sua funcionalidade e balizando através das estruturas psicossociais da própria espécie.

Educação, Psicologia e Interfaces, Volume 3, Número 1, p. 28-42, Janeiro/Abril, 2019.

ISSN: 2594-5343. DOI: https://doi.org/10.37444/issn-2594-5343.v3i1.125 
Três décadas depois,a análise do conflituoso percurso das políticas educacionais nos leva a defender, ainda, a alfabetização como processo discursivo porque essa concepção sintetiza, como poucas, a complexidade envolvida nos atos de ensinar e aprender; explicita a contribuição dos diferentes campos de conhecimento implicados nas atividades realizadas com a linguagem no contexto da escola e marca o rumo para os muitos educadores que não se iludem com as promessas de soluções unidirecionais para os problemas da educação. (LAPLANE, 2017, p.58)

A dimensão discursiva está colocada nesses termos e portanto, transcende a si mesmo, se pensarmos que esse processo é marcado pela materialidade das relações, da própria evolução lingüística em seus recursos e equipamentos e de seu componente estético e cultural. Portanto, a constituição de sentidos é o ponto inegociável, onde o desejo encontra um interlocutor.

Essa negociação é produto de elaborações intersubjetivas, em que os aparentes erros do alunos, nos mostram o quanto eles carregam de conhecimentos, hipóteses e de suas vivências sociais. Smolka nos diz o quanto os alunos têm a dizer, nos aponta questionamentos sobre a práticas docente e nos descortina a importância de entendermos esses atos enunciativos. Ela nos possibilita desnaturalizar nosso olhar sobre ritos e práticas, cenários e atividades que necessitam aprofundar a significação que dialogue com as vivências lingüísticas do cotidiano das práticas sociais de escrita e de leitura. Por isso, nos reforça Geraldi $(2017$, p. 8) que:

Foi preciso ser indisciplinada para conceber uma alfabetização como processo discursivo. Foi preciso ser corajosa para enfrentar dogmas existentes. Mas o mais surpreendente do percurso de Ana Luiza Smolka é o fato de se deixar banhar pelos estudos da linguagem em sua perspectiva enunciativa, quando no interior da Linguística esta perspectiva era absolutamente marginal. Ainda que referências possam ser apresentadas mostrando um clima de desconforto com a Linguística disciplinarmente bem comportada que pairava nos estudos da linguagem, a bibliografia manuseada - aquela existente e possível de ser manuseada - continha inumeráveis conceitos que contradiziam o ponto de vista assumido no texto de tese, depois tornado o livro A criança na fase inicial da escrita: a alfabetização como processo discursivo. Para os leitores da obra e dos textos que a homenageiam depois de 30 anos de influência inegável nos estudos da alfabetização, certamente não escapa a concepção de sujeite agente, agenciador, que se assume como autor e que apões sua assinatura desde as garatujas até o texto mais acadêmico e elaborado possível. Neste aspecto, afasta-se do que era predominante nos estudos discursivos ainda nascentes em que paradoxalmente se apostava na enunciação, mas se desprezavam as descontinuidades que um agenciador pode produzir.

Educação, Psicologia e Interfaces, Volume 3, Número 3, p. 28-42, Janeiro/Abril, 2019. 
Pensamos, então, que os escritos e reflexões de Smolka, continuam nos fazendo refletir sobre nossas práticas e nossas posturas. O revisitar sua obra nos possibilita pensar nos avanços que alcançamos e ainda no que precisamos avançar. A complexidade de seus estudos nos fornece material intensamente ético, pois que considera cada criança, cada sujeito autor e produtor de seu próprio conhecimento, além de realçar a postura investigativa, pesquisadora do professor como mediador e também autor de um movimento dialógico.

A professora Cecília Goulart reitera a iniciativa de Ana Luisa Smolka, evidenciando a importância da oralidade na constituição dos processos lingüísticos que a criança vai estabelecendo relações, como ela mesmo nos coloca:

O trabalho da linguagem, que nos compele a aprendê-la dentro de determinados moldes gramaticais, e o nosso trabalho com a linguagem, reconhecendo e explorando seu potencial criativo, nos humanizam pela aproximação e interação que estabelecemos com os outros, tornado-nos seres políticos, coletivizando-nos. A interação com o outro é condição necessária para a constituição da linguagem (GOULART, 2010, p.63).

Daí a importância das práticas sociais:

Entendemos práticas sociais como atividades realizadas pelo conjunto ou grupos de pessoas da sociedade para se desempenharem em diferentes esferas da vida: doméstica, cotidiana, escolar, profissional, de lazer, religiosa, entre outras. As práticas sociais não são homogeneamente vividas no todo social. Grupos diferentes possuem demandas sociais diferentes, expressando-se tanto por atividades diferentes quanto por desempenhos diferentes, ou seja, por modos diferentes de utilização da língua (GOULART, 2010, p.63).

Portanto, é nas práticas sociais que o sentido dos textos (orais e escritos) se constituem e a escola precisa estar atenta a essa dinâmica:

A escola é o lugar organizado para se fazer um exercício diário de ampliar e aprofundar, de forma crítica, o conhecimento do mundo. Para que as crianças dêem continuidade ao seu aprendizado sobre o mundo e a linguagem é importante que se criem situações pedagógicas de produção de textos orais e escritos (GOULART, 2010, p. 67).

O pensamento de Cecília Goulart se aproxima do trabalho de Smolka todo o tempo, pois reforça as observações, ponderações e os próprios paradigmas que estão

Educação, Psicologia e Interfaces, Volume 3, Número 1, p. 28-42, Janeiro/Abril, 2019.

ISSN: 2594-5343. DOI: https://doi.org/10.37444/issn-2594-5343.v3i1.125 
colocados no trabalho. Smolka demonstra um imenso respeito aos conhecimentos que as crianças trazem ao ingressarem na escola, o que também é reiterado por Goulart (2010, p.72):

Precisamos ser sensíveis ao esforço das crianças para significar em língua escrita. Os entendimentos das crianças se originam em diversos tipos de conhecimentos, por isso há cruzamentos. Há crianças que, para compor a sua escrita, levam desenhos, numerais e símbolos de outras naturezas, valendo-se do valor sonoro destes símbolos e também do valor do significado, um valor ideográfico. Outras crianças, junto a suas organizações de letras, lidas por elas com sentido de um texto, mas sem valor convencional, copiam palavras ou frases ou escrevem de memória, procurando dar legitimidade ao que produzem.

\section{CONSIDERAÇÕES FINAIS}

Então, comprovamos, que o trabalho de Smolka foi e ainda continua sendo bastante questionador e reflexivo sobre como as crianças pensam e produzem a escrita. E mesmo passados 30 anos, seus estudos ainda nos instigam a repensarmos nossas práticas e repensarmos nossas concepções de conhecimento, infância e língua. Tratar o aluno e seu processo de aquisição da língua escrita de maneira mecânica é embotar/engessar as possibilidades de relações e crescimento para além do "mundo" escolar.

\section{REFERÊNCIAS BIBLIOGRÁFICAS}

ANDRADE, Ludmila Thomé de. Novos espaços discursivos na escola, formadores de novos leitores, de uma nova língua escrita. Pátio: Ensino Fundamental, v. 59, p. 1417, 2011.

BAKHTIN, Mikail. (1981). Marxismo e filosofia da linguagem. São Paulo: Hucitec.

GERALDI, João Wanderley. Prefácio. In: GOULART, Cecília M. A.; GONTIJO. Cláudia Maria Mendes; FERREIRA, Norma Sandra de A. (Orgs.). A Alfabetização como Processo Discursivo: 30 anos de a criança na fase inicial da escrita. São Paulo: Cortez, 2017.

GERALDI, João Wanderley. Portos de Passagem. São Paulo: Cortez, 2013.

GOULART, Cecília. Oralidade e Escrita. Revista Educação: Guia da Alfabetização. $n^{\circ}$ 1. Mar, 2010.

Educação, Psicologia e Interfaces, Volume 3, Número 3, p. 28-42, Janeiro/Abril, 2019.

ISSN: 2594-5343. DOI: https://doi.org/10.37444/issn-2594-5343.v3i1.125 
LAPLANE, Adriana.. A Alfabetização Como Processo Discursivo em Perspectiva. In: GOULART, Cecília M. A.; GONTIJO. Cláudia Maria Mendes; FERREIRA, Norma Sandra de A. (Orgs.) A Alfabetização como Processo Discursivo: 30 anos de a criança na fase inicial da escrita. São Paulo: Cortez, 2017.

MARTINS, Lígia Márcia; RABATINI, Vanessa Gertrudes. A Concepção de Cultura em Vygotsky: Contribuições para a educação escolar. Revista Psicologia Política. São Paulo, vol.11 $\mathrm{n}^{\circ} \quad$ 22. dez, 2011. Disponível em: http://pepsic.bvsalud.org/scielo.php?script=sci_arttext\&pid=S1519549X2011000200011 Acesso em: em 21 jan 2018.

SCHILICKMANN, Maria Sirlene. As Cartilhas no Processo de Alfabetização. Revista Linguagem em (Dis)curso, vol 2, número 1, jul./dez, 2001. Disponível em: http://www.portaldeperiodicos.unisul.br/index.php/Linguagem_Discurso/article/downlo ad/201/229 Acesso em: em 21 jan 2018.

SMOLKA, Ana Luiza Bustamante. A Concepção de Linguagem como Instrumento: um questionamento sobre práticas discursivas e educação formal. Cognição e Linguagem. Temas de Psicologia. Ribeirão Preto. vol. $3 \mathrm{n}^{\circ}$. 2, ago, 1995. Disponível em: http://pepsic.bvsalud.org/scielo.php?script=sci_arttext\&pid=S1413389X1995000200003 Acesso em: em 21 jan 2018.

SMOLKA, Ana Luiza Bustamante. A Criança na Fase Inicial da Escrita: a alfabetização como processo discursivo. 13a ed. São Paulo, Cortez e Editora, 2012.

TAFFARELlO, Adriana. Estudos Sobre a Perspectiva Discursiva no Processo Inicial de Aquisição da Língua. Trabalho de Conclusão de Curso (Graduação). Universidade Estadual de Campinas. Campinas, 2016. Disponível em: http://www.bibliotecadigital.unicamp.br/document/?view=000978131 Acesso em: em 21 jan 2018.

VYGOTSKY, Lev Semenovitch. Thought and Language. Mass., MIT Press, 1975.

GLOSSÁRIO, BAKHTIN. In: Linguagens em Interação: teoria dialógica. 2011, s/p). Disponível em: http://linguagenseminteracao.blogspot.com.br/2012/11/glossariobakhtin.html. Acesso em: em 21 jan 2018.

\section{Credenciais da/os autora/es}

OLIVEIRA, Sabrina Guedes de. Mestre em Novas Tecnologias Digitais na Educação pela UNICARIOCA/RJ. Coordenadora Pedagógica da Rede Municipal de Ensino do Rio de Janeiro. E-mail: sabrina.guedes@gmail.com

MACEDO, Mônica Ramos da Costa. Especialista em Relações Etnicorraciais e Educação/CEFET-RJ, Especialista em Construção do Conhecimento na Escola

Educação, Psicologia e Interfaces, Volume 3, Número 1, p. 28-42, Janeiro/Abril, 2019.

ISSN: 2594-5343. DOI: https://doi.org/10.37444/issn-2594-5343.v3i1.125 
Básica/UFF, Professora da Rede Municipal de Ensino do Rio de Janeiro. E-mail: m_macedo2006@yahoo.com.br

\section{Endereço para correspondência:}

Sabrina Guedes de Oliveira: Rua Araújo Viana, 57. Santo Cristo. Cep: 20220-110 - Rio de Janeiro/RJ. Email: sabrina.guedes@gmail.com

Mônica Ramos da Costa Macedo: Av. Paulo de Frontin, no 591/apt ${ }^{\circ}$ 207. Rio Comprido CEP: 20261-241 - Rio de Janeiro/RJ. Email: m_macedo2006@yahoo.com.br

Como citar este artigo (Formato ABNT): OLIVEIRA, Sabrina Guedes de; MACEDO, Mônica Ramos da Costa. Discursividade e alfabetização: 30 anos dialogando com Ana Luiza Smolka. Educação, Psicologia e Interfaces, v. 3, n.1, p. 28 42, 2019. DOI: https://doi.org/10.37444/issn-2594-5343.v3i1.125

Recebido: 04/01/2019.

Aceito: 20/03/2019. 